\title{
Analisis Implementasi Corporate Social Responsibility Pada Usaha Kecil Menengah Berbasis Pada ISO 26000
}

\author{
Ayudyah Eka Apsari ${ }^{1}$, Agus Mansur ${ }^{2}$
}

\begin{abstract}
Corporate social responsibility (CSR) is a claim of stakeholders of a company in order for the company to operate not only in the interest of the company shareholders, but also in the interests of the stakeholders such as employees, local communities, government, customers and environment. The CSR can build some positive effect for the company and gives benefits to society. Additionally, the CSR program is one of the company's ways in realizing its vision and mission. This research explores main factors influencing the implementation of a CSR program based on ISO 26000 ran by a manufacturing company located in Kecamatan Dlingo, Kabupaten Bantul. Regarding societal aspect, the environment is found as the main factor with MSA score of 0.649. Social relationship among employees, on the other hand, is found as the main factor of employees aspect with MSA score of 0.867.
\end{abstract}

Keywords. corporate social responsibility, MOQS, factor analysis, social relationship, Bantul

\begin{abstract}
Abstrak. Corporate social responsibility (CSR) merupakan klaim stakeholder agar perusahaan tidak hanya beroperasi untuk kepentingan para pemegang saham, tapi juga untuk kemaslahatan pihak stakeholders dalam praktik bisnis, yaitu para pekerja, komunitas lokal, pemerintah, lembaga swadaya masyarakat, konsumen dan lingkungan. Program CSR ini dapat menciptakan citra positif bagi perusahaan yang menyelenggarakan dan sangat bermanfaat bagi masyarakat, selain itu CSR ini merupakan rencana kerja sebuah perusahaan untuk mencapai visi dan misi. Penelitian ini difokuskan pada salah satu sentra industri di wilayah Kabupaten Bantul, yaitu di wilayah kecamatan Dlingo. Dalam penelitian ini memberikan hasil faktor-faktor yang berpengaruh dalam implementasi CSR disesuaikan dengan standar ISO 26000. Dari aspek masyarakat, kondisi lingkungan merupakan faktor yang paling mempengaruhi jalannya implementasi CSR di wilayah ini dengan nilai MSA sebesar 0,649. Pada aspek pekerja di wilayah Dlingo, hubungan sosial antar pekerja merupakan faktor yang paling mempengaruhi jalannya implementasi CSR di wilayah Dlingo dengan nilai MSA sebesar 0,867.
\end{abstract}

Kata Kunci. corporate social responsibility, MOQS, analisis faktor, hubungan sosial, Bantul

\section{Pendahuluan}

Dewasa ini, orientasi sebuah perusahaan baik perusahaan besar maupun perusahaan kecil menengah adalah untuk mencari keuntungan. Dengan berpegang pada tujuan yang pasti untuk mencari keuntungan tersebut sebuah perusahaan dapat menggunakan berbagai macam cara untuk meraih keuntungan yang sebesar-besarnya.

\footnotetext{
1 Ayudyah Eka Apsari, Program Studi Teknik Industri, Universitas Islam Batik Surakarta. Jl. KH. Agus Salim No 10 Surakarta (email: ayudyaheka2511@gmail.com)

2 Agus Mansur, Jurusan Teknik Industri, Universitas Islam Indonesia, Jl. Kaliurang KM 14.5 Besi, Sleman, Yogyakarta
}

Diajukan: 01-09-2016 Disetujui: 10-12-2016
Tuntutan pemerintah pada perusahaan semakin ketat dengan diterapkannya konsep kepedulian terhadap pekerja dan masyarakat sekitarnya.

Oleh karena itu, perusahaan tidak hanya dituntut untuk mencari keuntungan semata, namun juga harus perduli terhadap lingkungan sekitar terutama pekerja dan masyarakat. Kepedulian ini lebih terlihat sebagai tanggung jawab sosial perusahaan terhadap masyarakat, dimana hal ini digunakan untuk menjaga kelangsungan perusahaan itu sendiri. Tanggung jawab sosial perusahaan inilah yang lebih sering dikenal dengan istilah Corporate Social Responsibility (CSR) (Marsden dan Andriof, 2008).

CSR sendiri merupakan klaim stakeholder agar perusahaan tidak hanya beroperasi untuk kepentingan para pemegang saham, tapi juga untuk kemaslahatan pihak stakeholder dalam 
praktik bisnis, yaitu para pekerja, komunitas lokal, pemerintah, lembaga swadaya masyarakat konsumen dan lingkungan (Nugroho, 2007). Pentingnya program CSR ini, tidak hanya berlaku bagi perusahaan-perusahaan besar seperti diketahui selama ini. CSR ini juga berlaku bagi perusahaan kecil menengah, terutama bagi sekelompok perusahaan yang berlokasi dan beroperasi di tengah-tengah masyarakat langsung. Program CSR ini selain dapat menciptakan citra positif bagi perusahaan yang menyelenggarakan, namun juga sangat bermanfaat bagi masyarakat. Adanya program CSR ini merupakan rencana kerja sebuah perusahaan untuk mencapai visi dan misi perusahaan (Lichtenstein, 2006).

Kajian mengenai CSR ini semakin berkembang pesat seiring banyaknya kasus yang terjadi dimana perusahaan tidak memberikan kontribusi positif secara langsung kepada masyarakat bahkan memberikan dampak negatif atas beroperasinya perusahaan. Isu-isu yang berkaitan dengan reputasi, manajemen resiko dan keunggulan kompetitif mendorong perusahaan untuk melakukan pengungkapan informasi sosial kepada masyarakat. Citra perusahaan akan semakin baik dimata masyarakat apabila dapat menunjukkan tanggung jawab dan kepeduliannya terhadap lingkungan eksternal. Kesuksesan program CSR ini dapat terjadi jika perusahaan memiliki tim kerja ataupun organisasi perusahaan yang baik untuk mewujudkan program ini ditengah-tengah masyarakat. Pelaksanaan program CSR ini tidak dapat diwujudkan secara instan tanpa adanya observasi terlebih dahulu, karena alasan ini maka dibutuhkan tim kerja yang cukup baik di dalam perusahaan (Cahaya dkk, 2011). Globalisasi telah membawa semua persoalan menjadi semakin kompleks, persaingan semakin keras dan memerlukan perubahanperubahan baik dalam struktur organisasi, manajemen maupun sumber daya pendukung operasional di lini produksi (Wignjosoebroto, 2011). Untuk itu sistem produksi harus benarbenar dioperasikan secara efektif dan efisien.

Organisasi industri yang awalnya dirancang mengikuti pola struktur hirarki-birokrasi yang menempatkan manusia sebagai pekerja, selanjutnya beranjak dan bergeser maju dalam pola struktur jaringan kerja (network). Di sini aktivitas kerja manusia dan struktur organisasi kerjanya akan beraliansi dalam sebuah mata rantai kerja sama dengan semangat dan kebersamaan (collaboration \& partnership). Perwujudan tim kerja yang baik ini dapat dengan menggunakan prinsip ergonomi makro, dimana di dalam ergonomi makro ini mempengaruhi aplikasi sistem antar manusia dan teknologi untuk mendesain atau memodifikasi sebuah sistem yang aman, nyaman, efektif, dan berkualitas (Hendrick, 1984). Dengan adanya aplikasi ergonomi makro ini dalam perwujudan suatu sistem kerja di perusahaan dapat mempermudah kerja perusahaan untuk mewujudkan visi, misi perusahaan terutama dalam perwujudan program CSR bagi masyarakat.

\section{Metode Penelitian}

Penelitian ini dilakukan di industri kecil dan menengah Kecamatan Dlingo, Kabupaten Bantul, Daerah Istimewa Yogyakarta. Subjek penelitian ini adalah kelompok pekerja dan masyarakat dalam kategori ring satu.

Variabel penelitian deskriptif yang mempelajari pengaruh dari suatu treatment akan terdiri dari variabel terikat atau yang dipengaruhi dan variabel bebas yang mempengaruhi. Dalam artikel ini, yang menjadi variabel dependent adalah posisi UKM dari sisi CSR. Sedangkan variabel independent adalah aspek-aspek yang berkaitan dengan ergonomi makro dari setiap komponen sistem yang terdiri dari lingkungan, pekerja, tanggung jawab produk, serta lingkungan sosial atau masyarakat. Kerangka berpikir dalam penelitian adalah dasar pemikiran dari penelitian yang disintesiskan dari fakta, observasi dan telaah kepustakaan. Uraian dalam kerangka berpikir menjelaskan hubungan dan ketertarikan antar variabel penelitian secara logis. Kerangka pemikiran yang baik yaitu apabila mengidentifikasikan variabel-variabel penting yang sesuai dengan permasalahan penelitian, dan secara logis mampu menjelaskan keterkaitan antar variabel tersebut (Riduwan dan Akdon, 2007).

Pada penelitian ini, data primer diperoleh dari kuisioner penelitian. Responden yang menjadi objek penelitian ini adalah pekerja dan masyarakat di daerah Kecamatan Dlingo, Kabupaten Bantul. Untuk mendapatkan informasi yang diharapkan, kuisioner diharapkan sebagai alat pengumpulan data primer. Kuisioner ini merupakan kumpulan pertanyaan yang 
Tabel 1. Variabel dan sub-variabel yang digunakan berdasar pada ISO 26000

\begin{tabular}{|c|c|}
\hline & Corporate Social Responsibility \\
\hline Pekerja & 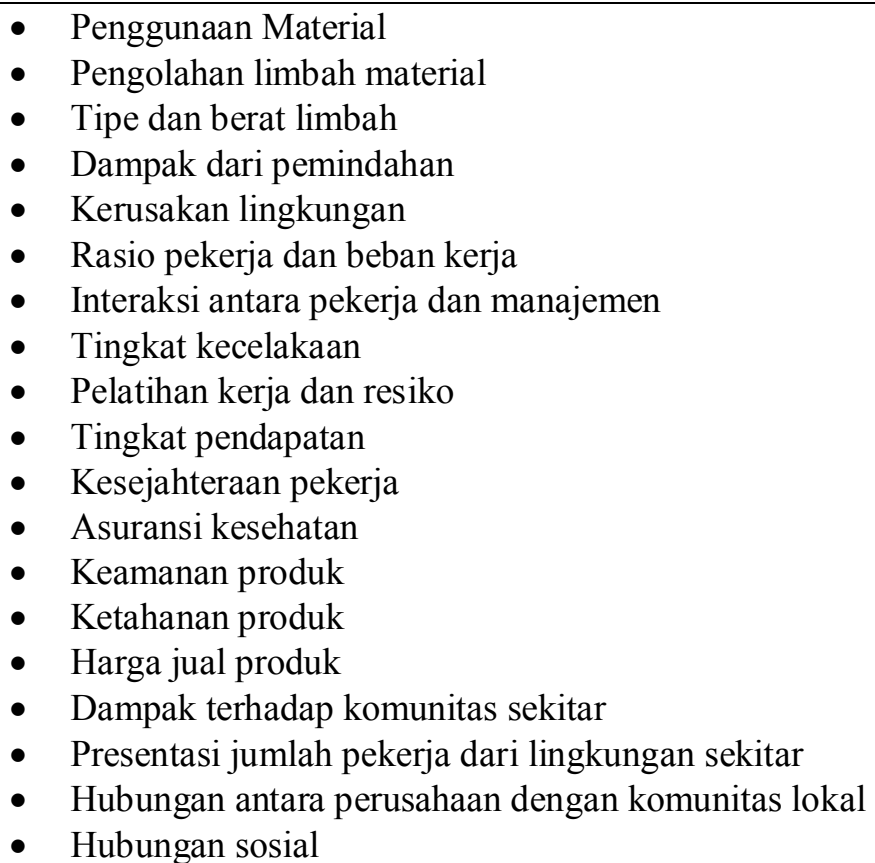 \\
\hline
\end{tabular}

ditujukan kepada para karyawan dan masyarakat sekitar untuk mendapatkan gambaran informasi mengenai faktor-faktor yang mempengaruhi implementasi berjalannya CSR atau tidak di wilayah tersebut.

Kuisioner tidak dapat diolah bila jawaban kuisioner tersebut tidak memenuhi syarat-syarat pengisian kuisioner. Adapun syarat pengisian kuisioner yaitu semua pertanyaan harus dijawab sesuai dengan pilihan yang ada dan tidak boleh terdapat jawaban ganda dalam satu pertanyaan. Kuisioner yang digunakan pada penelitian ini merupakan kuisioner yang didasarkan pada MOQS (Macroergonomics Organizational Quistionnaire Survey). Seperti yang telah diungkapkan oleh Carayon dan Smith (2000), dalam MOQS ini menjelaskan beberapa informasi mengenai tugas (tasks), kondisi organisasi, masalah lingkungan, peralatan kerja, serta karakteristik individual dan teknologi.

Kuisioner yang ditujukan kepada para pekerja terdiri dari 20 butir soal pertanyaan dengan tipe jawaban optional dengan menggunakan skala Likert (1-5). Sedangkan untuk kuisioner yang ditujukan untuk masyarakat sekitar terdiri dari 19 butir soal, dimana seluruh soal merepresentasikan kondisi lingkungan yang ada di sekitar sentra industri. Untuk mengetahui validitas dari butirbutir dalam kuisioner maka disebarkan kepada 45 responden. Karateristik responden dalam penelitian adalah warga setempat serta para pekerja yang bekerja di sentra industri tersebut dengan batas minimal usia 15 tahun sesuai dengan penjelasan dalam ISO 26000.

Data yang telah dikumpulkan tersebut diuji validitas dan realibilitasnya. Uji validitas dilakukan untuk mengukur ketepatan pertanyaan dalam kuisioner. Jika terdapat instrumen yang tidak valid maka item tersebut tidak dapat digunakan selanjutya untuk penelitian, sehingga item tersebut harus dibuang. Uji reliabilitas dilakukan untuk melihat tingkat kepercayaan terhadap data yang diperoleh dari instrumen pengumpulan data sehingga jika dilakukan pengumpulan data ulang dengan instrumen dan objek yang sama maka hasilnya akan sama atau perbedaannya tidak signifikan. Sama halnya dengan kuisioner tertutup, selanjutnya diolah dengan teknik statistik yaitu analisis faktor, untuk menentukan faktor yang paling berpengaruh 
terhadap jalannya implementasi program CSR di wilayah Dlingo.

\section{HASIL DAN PEMBAHASAN}

\section{Uji Validitas}

Uji validitas akan menguji masing-masing variabel yang digunakan dalam penelitian ini, dimana keseluruhan variabel penelitian memuat 20 dan 19 pernyataan yang harus dijawab oleh responden. Adapun kriteria yang digunakan dalam menentukan validitas pertanyaan yang digunakan dalam penelitian ini adalah sebagai berikut:

a. Tingkat kepercayaan : $95 \%(\alpha=5 \%)$

(1)

b. Derajat kebebasan (df): $n-2$

c. Jika $\mathrm{r}_{\text {hitung }}$ (untuk tiap butir dapat dilihat pada kolom Corrected Item -Total Correlation) lebih besar dari $r_{\text {tabel }}$ dan nilai $r_{\text {positif, maka butir }}$ pernyataan dikatakan valid (Ghozali dan Fuad, 2005).

d. Berdasarkan data yang diperoleh oleh peneliti dengan jumlah responden sebanyak 45 responden, maka $r_{\text {tabel }}$ yang digunakan adalah sebesar 0,2483.

Berdasarkan analisis yang telah dilakukan, maka hasil pengujian validitas dapat ditunjukkan pada hasil perhitungan dengan menggunakan SPSS seperti pada Tabel 2.

Tabel 2. Hasil validasi butir soal untuk aspek masyarakat

\begin{tabular}{cccc}
\hline $\begin{array}{c}\text { Butir } \\
\text { Soal }\end{array}$ & R tabel & R hitung & $\begin{array}{c}\text { Keterangan } \\
\text { Validasi }\end{array}$ \\
\hline Q1 & 0,2483 & 0,632 & Valid \\
Q2 & 0,2483 & 0,693 & Valid \\
Q3 & 0,2483 & 0,632 & Valid \\
Q4 & 0,2483 & 0,264 & Valid \\
Q5 & 0,2483 & 0,459 & Valid \\
Q6 & 0,2483 & 0,625 & Valid \\
Q7 & 0,2483 & 0,693 & Valid \\
Q9 & 0,2483 & 0,693 & Valid \\
Q10 & 0,2483 & 0,547 & Valid \\
Q11 & 0,2483 & 0,625 & Valid \\
Q12 & 0,2483 & 0,436 & Valid \\
Q13 & 0,2483 & 0,261 & Valid \\
Q14 & 0,2483 & 0,445 & Valid \\
Q16 & 0,2483 & 0,464 & Valid \\
Q18 & 0,2483 & 0,257 & Valid \\
Q19 & 0,2483 & 0,625 & Valid \\
\hline
\end{tabular}

Dari hasil uji validasi di atas, maka dapat diketahui untuk wilayah regional Dlingo, Kabupaten Bantul terdapat tiga butir soal yang tidak valid. Untuk itu, peneliti melakukan uji validasi lanjut untuk mengetahui kevalidan data setelah menghapus ketiga butir soal yang tidak valid sebelumnya. Setelah dilakukannya uji validasi lanjut, untuk wilayah regional Dlingo dapat disimpulkan bahwa ke enambelas butir soal yang ada sudah valid.

Dari hasil yang didapat, terdapat dua butir soal yang tidak valid. Sehingga diharuskan untuk dilakukan uji validasi lanjut. Tabel 3 merupakan hasil dari uji validasi lanjut.

Tabel 3. Hasil validasi butir soal untuk aspek pekerja

\begin{tabular}{cccc}
\hline $\begin{array}{c}\text { Butir } \\
\text { soal }\end{array}$ & R tabel & R hitung & $\begin{array}{c}\text { Keterangan } \\
\text { Validasi }\end{array}$ \\
\hline Q1 & 0,2483 & 0,620 & Valid \\
Q2 & 0,2483 & 0,540 & Valid \\
Q3 & 0,2483 & 0,564 & Valid \\
Q4 & 0,2483 & 0,564 & Valid \\
Q5 & 0,2483 & 0,620 & Valid \\
Q6 & 0,2483 & 0,641 & Valid \\
Q8 & 0,2483 & 0,379 & Valid \\
Q9 & 0,2483 & 0,564 & Valid \\
Q10 & 0,2483 & 0,540 & Valid \\
Q11 & 0,2483 & 0,641 & Valid \\
Q12 & 0,2483 & 0,324 & Valid \\
Q13 & 0,2483 & 0,404 & Valid \\
Q14 & 0,2483 & 0,473 & Valid \\
Q17 & 0,2483 & 0,420 & Valid \\
Q19 & 0,2483 & 0,404 & Valid \\
Q20 & 0,2483 & 0,390 & Valid \\
\hline
\end{tabular}

\section{Uji Reliabilitas}

Reliabilitas adalah alat untuk mengukur suatu kuesioner yang merupakan alat pengukuran konstruk atau variabel. Suatu kuesioner dikatakan reliabel atau handal jika jawaban seseorang terhadap pertanyaan adalah konsisten atau stabil dari waktu ke waktu (Ghozali, 2001). Uji reliabilitas adalah tingkat kestabilan suatu alat pengukur dalam mengukur suatu gejala atau kejadian. Semakin tinggi reliabilitas suatu alaat pengukur, maka semakin stabil pula alat pengukur tersebut. Menurut Nunnally (1967) dalam Ghozali (2001), suatu konstruksi dikatakan reliabel jika memberikan nilai Cronbach's Alpha $>0,6$. 
Tabel 4. Nilai Cronbach's Alpha aspek masyarakat

\begin{tabular}{ccc}
\hline Cronbach's & Cronbach's Alpha Based & Nof \\
Alpha & on Standardized Items & Items \\
, 855 &, 884 & 16 \\
\hline
\end{tabular}

Tabel 5. Nilai Cronbach's Alpha aspek pekerja

\begin{tabular}{ccc}
\hline Cronbach's & Cronbach's Alpha Based & Nof \\
Alpha & on Standardized Items & Items \\
, 862 &, 875 & 16 \\
\hline
\end{tabular}

Tabel 4 menunjukkan nilai Cronbach's Alpha pada aspek masyarakat. Dengan nilai Cronbach's Alpha sebesar 0,855 maka hasil uji reliabilitas dari data dari masyarakat yang diperoleh di wilayah Dlingo dinyatakan sudah reliabel.

Tabel 5 menunjukkan nilai Cronbach's Alpha pada aspek pekerja. Besar nilai Cronbach's Alpha sebesar 0,862, hal ini membuktikan bahwa data untuk pekerja di wilayah Dlingo sudah reliable.

\section{Analisis Faktor}

Data dari hasil perhitungan SPSS analisis faktor untuk hasil kuisioner yang ditujukan kepada masyarakat di wilayah regional Dlingo. Dari hasil yang diperoleh, harus dilakukan analisis lanjut, karena masih ada hasil perhitungan yang dibawah 0,5. Adapun hasil perhitungan lanjut dengan uji KMO dan Bartlett, seperti diperlihatkan pada Tabel 6 .

Tabel 6. Hasil KMO and Bartlett's test lanjut pada aspek masyarakat

\begin{tabular}{lr}
\hline Kaiser-Meyer-Olkin Measure of & 0,574 \\
Sampling Adequacy & \\
Bartlett's Test of Sphericity Approx. & 37,158 \\
Chi-Square & \\
Df & 15 \\
Sig. & 0,001 \\
\hline
\end{tabular}

Tabel 7. Anti image matrices lanjut pada aspek masyarakat

\begin{tabular}{ccc}
\hline Label & Keterangan & MSA \\
B & Q2 & 0,558 \\
D & Q4 & 0,649 \\
F & Q6 & 0,504 \\
L & Q14 & 0,578 \\
M & Q15 & 0,532 \\
N & Q16 & 0,585 \\
\hline
\end{tabular}

Dari hasil uji KMO and Bartlett's yang sudah memenuhi syarat, kemudian dilakukan analisis lanjut dengan memperhatikan nilai anti image matrices dari analisis faktor. Hasil dari perhitungan lanjut ini ditampilkan pada Tabel 7.

Dari hasil akhir yang didapat, dapat diketahui bahwa variabel-variabel dalam tabel di atas merupakan variabel yang mempengaruhi jalannya implementasi corporate social responsibility (CSR) di wilayah Kecamatan Dlingo. Ke enam variabel tersebut menunjukkan bahwa variabel kondisi lingkungan (D) merupakan variabel yang paling mempengaruhi dengan nilai measure sampling adequacy (MSA) sebesar 0,649. Diikuti oleh variabel kepedulian sosial $(\mathrm{N})$ dengan besar MSA 0,585; variabel hubungan sosial perusahaan (L) dengan besar MSA 0,578; variabel pengolahan limbah (B) dengan besar MSA 0,558; variabel hubungan sosial perusahaan dengan pemerintah setempat $(\mathrm{M})$ dengan besar MSA 0,532 ; dan variabel perubahan budaya $(\mathrm{F})$ dengan besar MSA 0,504 .

Hasil dari uji analisis faktor yang ditujukan terhadap aspek pekerja di wilayah Dlingo, ditunjukkan pada Tabel 8 .

Tabel 8. Hasil KMO and Bartlett's test pada aspek pekerja

\begin{tabular}{lr}
\hline Kaiser-Meyer-Olkin Measure of & 0,717 \\
Sampling Adequacy & \\
Bartlett's Test of Sphericity Approx. & 135,795 \\
Chi-Square & \\
Df & 45 \\
Sig. & 0,000 \\
\hline
\end{tabular}

Tabel 9. Anti image matrices pada aspek pekerja

\begin{tabular}{ccc}
\hline Label & Keterangan & MSA \\
\hline A & Q1 & 0,732 \\
B & Q2 & 0,843 \\
C & Q3 & 0,555 \\
F & Q6 & 0,645 \\
G & Q8 & 0,678 \\
K & Q12 & 0,669 \\
L & Q13 & 0,737 \\
M & Q14 & 0,867 \\
N & Q17 & 0,857 \\
P & Q20 & 0,607 \\
\hline
\end{tabular}

Dari hasil perhitungan uji analisis faktor dari data yang diperoleh dari pekerja regional Dlingo pada Tabel 8, diperoleh hasil perhitungan uji 
KMO and Bartlett' dengan besar MSA sebesar 0,717. Untuk perhitungan anti image dalam aspek ini, didapat hasil bahwa nilai dari variabel hubungan sosial antar pekerja menempati peringkat tertinggi dengan besar nilai MSA 0,867 . Hal ini menjelaskan bahwa variabel tersebut merupakan variabel yang paling mempengaruhi di dalam berjalannya implementasi CSR di wilayah ini. Selain itu, terdapat sembilan variabel pendukung lainnya yang memiliki tingkat pengaruh yang berbedabeda. Hal tersebut dapat dilihat dari Tabel 9.

Setelah dilakukan perhitungan analisis faktor, didapatkan hasil MSA bahwa seluruh faktor yang mempengaruhi program CSR di wilayah Dlingo berdasarkan kuisioner yang ditujukan kepada pekerja, sudah berada diatas 0,5. Dari tabel di atas menyatakan bahwa variabel hubungan sosial antar pekerja (Q14) merupakan variabel yang paling berpengaruh, yang diikuti oleh variabel lainnya yaitu: variabel Q17 yang merupakan variabel kontrak kerja pekerja dengan perusahaan dengan besar nilai MSA 0,857. Selanjutnya adalah variabel komunikasi manajerial perusahaan dengan pekerja (Q2) dengan nilai MSA sebesar 0,843; variabel kebebasan politik (Q13) dengan nilai 0,737 ; variabel komunikasi manajerial (Q1) dengan nilai 0,732; variabel kesehatan pekerja (Q8) dengan nilai 0,678; variabel hak asasi manusia (Q12) dengan nilai sebesar 0,669; variabel kesejahteraan karyawan (Q6) dengan nilai 0,645; variabel hak asasi manusia (Q20) dengan nilai 0,607; dan yang terkecil dengan nilai 0,555 merupakan variabel kebebasan berpendapat (Q3).

\section{Cause-Effect Analysis}

Dari hasil perhitungan analisis faktor tersebut, variabel perubahan budaya merupakan variabel yang memiliki nilai terendah. Hal ini disebabkan oleh beberapa faktor yang digambarkan causeeffect diagram seperti pada Gambar 1 .

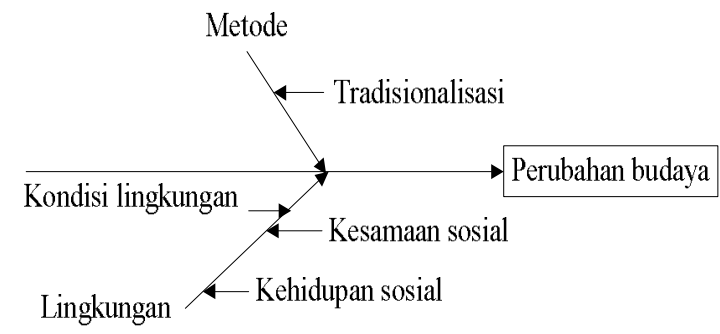

Gambar 1. Cause effect diagram perubahan budaya
Gambar 1 menunjukkan faktor-faktor yang menjelaskan bahwa perubahan budaya tidak terlalu mempengaruhi jalannya implementasi CSR di wilayah ini. Terdapat empat faktor yang dijadikan penyebab dari variabel ini, yaitu: kehidupan sosial, kesamaan sosial, kondisi lingkungan, tradisionalisasi. Kehidupan sosial disini menjelaskan bahwa kondisi antara masyarakat dengan pemilik perusahaan cukup baik, sehingga memungkinkan untuk terhindar dari adanya kesenjangan sosial. Sedangkan untuk kesamaan sosial, hal ini disebabkan karena kondisi masyarakat sekitar perusahaan dengan pemilik perusahaan relatif sama ataupun tidak terlalu jauh.

Selain itu, kemungkinan kecil perubahan budaya terjadi karena kondisi lingkungan yang cukup jauh dari modernisasi perkotaan, dengan wilayah geografis yang berada di daerah pegunungan. Tradisionalisasi di sini bermakna dari sisi pengetahuan akan kehidupan modernisasi, hal ini ditunjang dengan adanya kehidupan sosial masyarakat yang relatif masih mengikuti budaya yang ada dengan segala kepercayaan yang ada di daerah tersebut.

Kebebasan berpendapat merupakan variabel yang memiliki tingkat pengaruh terkecil dari beberapa variabel yang lain, hal ini disebabkan karena pihak perusahaan tidak memberikan banyak kesempatan bagi para pekerja untuk memberikan ide-ide baru maupun masukan bagi kemajuan perusahaan. Sebagai contoh, untuk desain produk, maupun teknik pemasaran dari industri tersebut. Hal ini dapat juga dijelaskan dengan diagram sebab-akibat (cause-effect diagram), seperti ditunjukkan pada Gambar 2.

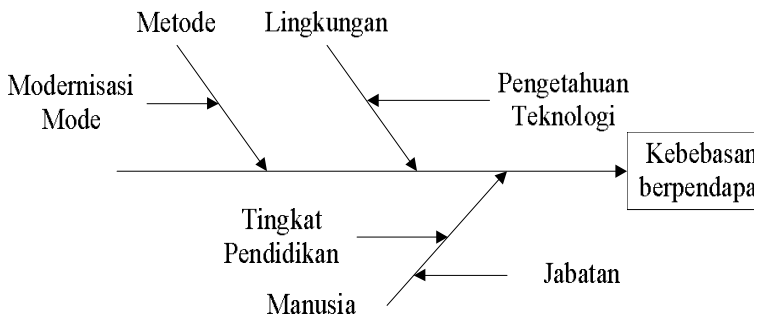

Gambar 2. Cause-effect diagram kebebasan berpendapat

Dari Gambar 2 dapat dijelaskan bahwa jabatan merupakan faktor yang dapat mempengaruhi variabel kebebasan berpendapat bagi para pekerja. Dengan jabatan yang lebih rendah dari 
pihak manajemen perusahaan, tidak menutup kemungkinan bagi para pekerja untuk memiliki gap atau jarak terhadap pihak manajemen perusahaan. Perbedaan jabatan ini ditunjang dengan faktor lain yaitu tingkat pendidikan dan pengetahuan teknologi yang dapat dijadikan sebagai faktor dari sisi manusia atau human itu sendiri. Pengetahuan teknologi yang dimiliki oleh para pekerja sudah pasti tidak setinggi ataupun selengkap pihak perusahaan, hal ini didukung pula oleh tingkat pendidikan yang dimiliki. Tingkat pendidikan masyarakat di wilayah ini rata-rata hanya setamat sekolah menengah pertama, dan hanya beberapa yang bersekolah hingga sekolah menengah atas. Sedangkan, pihak manajemen perusahaan minimal memiliki pengetahuan lebih dari sisi teknologi dan juga bisnis (pemasaran ataupun penjualan produk).

Dalam penyampaian pendapat di industri ini, tidak hanya dibutuhkan pengetahuan akan teknologi melainkan juga pengetahuan akan mode yang ada sekarang ini. Industri yang ada di daerah Dlingo ini merupakan industri dengan berbahan dasar kayu, seperti meubel ataupun kerajinan tangan dan souvenir. Hal itulah yang mengharuskan pihak industri untuk mengikuti mode yang ada, selain dengan mempertahankan produk utama mereka, mereka juga harus menunjang produknya dengan inovasi baru. Salah satunya merupakan inovasi dari segi model produk atau design produk. Oleh karena itu, pekerja seringkali tidak memperoleh kesempatan untuk menyampaikan pendapat terutama dalam segi design produk, karena keterbatasan pengetahuan akan dunia mode terbaru ataupun issue yang sedang marak di lingkungan industri kayu. Hal ini juga merupakan faktor yang mempersulit para pekerja untuk mengutarakan pendapat.

\section{KESIMPULAN}

Dari hasil analisis faktor, diperoleh beberapa faktor yang paling berpengaruh dari masingmasing aspek di setiap wilayah sentra industri. Ditinjau dari aspek masyarakat, di wilayah Dlingo kondisi lingkungan merupakan faktor yang paling mempengaruhi jalannya implementasi CSR di wilayah ini dengan nilai MSA sebesar 0,649. Pada aspek pekerja di wilayah Dlingo, hubungan sosial antar pekerja merupakan faktor yang paling mempengaruhi jalannya implementasi CSR di wilayah Dlingo dengan nilai MSA sebesar 0,867.

\section{DAFTAR PUSTAKA}

Badan Standardisasi Nasional. 2013. Guidance on Social responsibility ISO 26000:2010, IDT.

Cahaya dkk. 2011. Isomorphic Propensities to Communicate Occupational Health and Safety Issue. England: British Accounting and Finance Association (BAFA) Conference.

Cahaya, F.R.; Porter, S.; Tower, G.; Brown, A. 2011. "Isomorphic propensities to communicate occupational health and safety issues". Paper presented at the British Accounting and Finance Association (BAFA) Annual Conference. Birmingham, England, 13 April 2011.

Carayon, P.; Smith, M.J. 2000. "Work organization and ergonomics". Applied Ergonomics, Vol. 31 (6), pp.: 649 -662 .

Ghozali, I. 2001. Analisis Multivanate dengan program SPSS. Edisi ke 2. Universitas Diponegoro.

Ghozali, I.; Fuad, M. 2005. Structural Equation Modeling Teori Konsep \& Aplikasi Dengan Program Lisrel 8.54. Semarang: Badan Penerbit UNDIP.

Hendrick, H.W. 1984. "Wagging the tail with the dog: Organizational design considerations in ergonomics". Proceeding of the Human Factors Society 28th Annual Meeting. Santa Monica, CA: Human Factors Society, pp. 899-903.

Lichtenstein, J. 2006. American Capitalism: Social Thought and Political Economy in the Twentieth Century. United States: University of Pennsylvania Press.

Marsden, C.; Andriof, J. 1998. Unfolding Stakeholder Thinking. UK: Warwick Business School.

Nugroho. 2007. Analisis Perilaku Konsumen. Jakarta: Ghalia Indonesia.

Nunnally, J. 1967. Psycometric Theory. New York: McGraw Hill.

Riduwan, R.; Akdon, A. 2007. Rumus dan Data Dalam Analisis Statistik. Bandung: Alfabeta.

Wignjosoebroto, S. 2011. Ergonomi Industri: Pendekatan Ergonomi Menjawab Problematika Industri. Jakarta. Online pada laman web http://msritomo.blogspot.com. 